\title{
Pricing Decisions of Competing Tobacco Enterprises with Online Channel
}

\author{
Rong Zhang, ${ }^{1}$ Jackson Jinhong $\mathrm{Mi}^{2}{ }^{2}$ and Bin $\mathrm{Liu}^{2}$ \\ ${ }^{1}$ Research Center of Logistics, Shanghai Maritime University, Shanghai 201306, China \\ ${ }^{2}$ School of Economics and Management, Shanghai Maritime University, Shanghai 201306, China \\ Correspondence should be addressed to Bin Liu; liubin@shmtu.edu.cn
}

Received 25 September 2015; Accepted 4 November 2015

Academic Editor: Paolo Renna

Copyright (c) 2015 Rong Zhang et al. This is an open access article distributed under the Creative Commons Attribution License, which permits unrestricted use, distribution, and reproduction in any medium, provided the original work is properly cited.

\begin{abstract}
According to the new measurement of launching online distribution channels of tobacco enterprises in China, this paper investigates the tobacco firm's pricing decisions on the supply chain which consists of two manufacturers and one retailer under three dual-channel structures. Three dual-channel structures include no online channel, only one online channel by one manufacture, and two online channels by two manufacturers. We apply the Stackelberg game to analyze the equilibrium pricing strategies under different structures and try to explore the necessity and advantages of launching online sales channels. The results demonstrate that the substitutability of a product has significant impact on introducing online sales channels, and the online dualchannel structure could result in less profit for manufacturers compared to the traditional retail channel structure; and thus, a dual-channel structure with online sales is not the best strategy for traditional manufacturers. Moreover, when the product is less substitutable, the effect of the tobacco control on the online sales channel is inferior to the traditional channels and vice versa.
\end{abstract}

\section{Introduction}

With the popularity of the various Internet application, online sales have become an important channel for product sales. Most enterprises that opt to launch a second sales channel on the Internet agree that online sales channels are competitive in price and convenience when compared with traditional sales channels. The American Direct Marketing Association states that US online sales took up $10.3 \%$ of the GDP in 2005 which accounted for approximately $42 \%$ of the top factors in various industries, including Hewlett-Packard, IBM, Eastman-Kodak, Nike, and Apple, and have achieved online sales by means of online technology [1].

The products on online sales channel are diversified, changing gradually from electronic-dominant to various industries-involved. In November 2011, Chinese tobacco companies had a major policy change by conducting trial online sales. A review of the current domestic conditions in China shows that tobacco companies are affected by the national monopoly policy, which holds that all products must be sold under the management of the Tobacco Monopoly
Bureau. This causes a certain distance with market competition to occur. After China's accession to the WTO and with the gradual marketization of the tobacco market and relaxation of the monopoly system, tobacco leaf import tariffs declined from $40 \%$ to $10 \%$, whereas tobacco product import tariffs were reduced from $65 \%$ to $25 \%$, raising the urgency of enhancing channel marketing. Currently, a "special tobacco monopoly retail license" is no longer required, allowing three million retailers with the tobacco monopoly retail license to sell foreign cigarettes. With the prevalence of antismoking campaigns worldwide, the foreign tobacco market has been greatly declined, causing transnational tobacco giants to aim their sights towards the Chinese market. In a report in 2005, Morgan Stanley stated the following: "The monopoly structure will be released after China enters into the World Trade Organization. For leading tobacco companies, China is the last unexploited great power." With this prospect, Chinese tobacco enterprises shift their focus towards younger generation and launch their online channels. China's advertising law prohibits tobacco advertisements in radios, films, televisions, newspapers, and periodicals (journals); thus, 
launching marketing strategies on the Internet and by social media is the rational option.

In 2009, China Hong Yun Hong He Group pioneered the SNS-online-community-concept based on "tobacco-digital integrated promotional marketing channels," which resulted in increased popularity for their products. Currently, tobacco online sales platforms have been established and have become popular across the country. Examples of these platforms include the tobacco-off site (http://www.yancaoke.com/), a New Business League online ordering platform, Xian Tobacco Monopoly Bureau website platform (http://www.xayc .com.cn), and Jiangsu tobacco online ordering platform (http://www.njtobacco.com). Under China's tobacco monopoly system mode, tobacco companies have a common vendor. Online sales now bring huge challenges to the traditional tobacco monopoly. For tobacco companies opting to go into the online sales channel, both the selection of channel structure and pricing are essential.

This paper primarily refers to the topics of dual-channel structure, dual-channel product pricing, and product substitutability, among which the dual-channel structural problems occupy an important place in the academia. On the choice of the dual-channel structure, Park and Keh [2] compare chain profits under different rights structures, such as direct marketing, retail, and mixed channels, to assist manufacturers in making the optimal channel selection. The research shows that, in mixed channels, the profits gained by manufacturers and retailers depend on the cost structure and benchmark market share. Adopting mixed channels will help manufacturers to increase the products' overall demand and their own profits and enhance the overall performance of the supply chain and social welfare. Chiang et al. [3] take into account the degree of consumer acceptance in online channels to further analyze the impact of the profit for supply chain members under online channels and pointed out that, even with no sales coming through the online channels, the online channels can increase profits. Kumar and Ruan [4] believe that vendors can gain profits from online channels assuming that the consumer is loyal to the brands or to the retailers. Cai [5] compares the influences of four kinds of channels (single direct marketing, single retail, direct sales channels combined with retail channels, and dual-retailer channels) on manufacturers, retailers, and the entire supply chain and concludes that the use of dual channel, combined with online and retailer channels, yields more profit for manufacturers than the single online channel does, which under certain circumstances yielded more profit than the single retail channel and that such dual channels assisted manufacturers and retailers in seizing the initiative.

In terms of studies on dual-channel pricing, Yao and Liu [6] analyze the dual-channel price competition for manufacturers and retailers under the Stackelberg and Bertrand games. Cattani et al. [7] review three pricing strategies of manufacturers, namely, keeping wholesale prices stable, pricing wholesale products with retail prices unchanged, and using wholesale price to obtain maximized profits. He found that when online channels are not convenient or selling costs are too high, manufacturers are likely to maintain the dual channels at the same price. Cachon and Kök [8] analyze the impacts of wholesale price contract, quantity discounts contract, and two-part tariff contract on members of the supply chains when multiple manufacturers sell through the same retailer. They point out that although the last two types of contracts can coordinate the supply chain, the wholesale price contract can better alleviate competition among manufacturers. Taking the prices of books and CD in the Swedish market as objects, Friberg et al. [9] investigate the relationship between such objects in traditional shops and those in online stores and found that the price of a product in a single online store was lower than that in a two-channel online shop. Zhang et al. [10] analyze the dualchannel structure, substitutability of products, and channel position and whether these factors influenced pricing for manufacturers and retailers. Liu et al. [11] examine the efficacy of cost sharing in a model of two competing manufacturer retailer supply chains who sell partially substitutable products that may differ in market size. Li et al.s [12] study examines a dual-channel supply chain in which the manufacturer makes green products for the environmental conscious and discusses the pricing and greening strategies for the chain members in both centralized and decentralized cases using the Stackelberg game model under a consistent pricing strategy. Chen [13] applies the traditional and direct online channels as its setting and evaluates the impact of price schemes and cooperative advertising mechanisms on dualchannel supply chain competition.

Furthermore, Khouja and Zhou [14] analyze a supply chain of a service provider who sells products and gift cards at face value at its locations. Cao et al. [15] develop an analytical framework to study the impact of an "online-tostore" channel on the demand allocations and profitability of a retailer who sells products to customers through multiple distribution channels. This paper also studies the substitutability of the product because substitutability is a key element in the competition between manufacturers or retailers. To differ from other studies, this paper mainly focuses on the two-channel structure of the supply chain and investigates the mode of two suppliers selling products by a common retailer.

\section{Modeling Background}

We consider three types of dual-channel supply chain structures (Figure 1), the traditional two-manufacture-singleretailer model, single-manufacturer involved in online marketing model, and two manufacturers involved in online marketing model. In the traditional model (Model A), manufacturers and retailers are both independent decisionmaking bodies and the decision-making process is a twostage progress of the Stackelberg game. The products are available to consumers by the retailers. In the online model (Models B, C, and D), manufacturers launch online channels, with both manufacturers and retailers providing products at the same time. In Models A, B, C, and D, the manufacturer is the leader of the supply chain, whereas retailers are the followers. Manufacturers operate $\operatorname{cost} c_{t}$ in traditional channels and then decide the wholesale price $w_{i}$ for the 


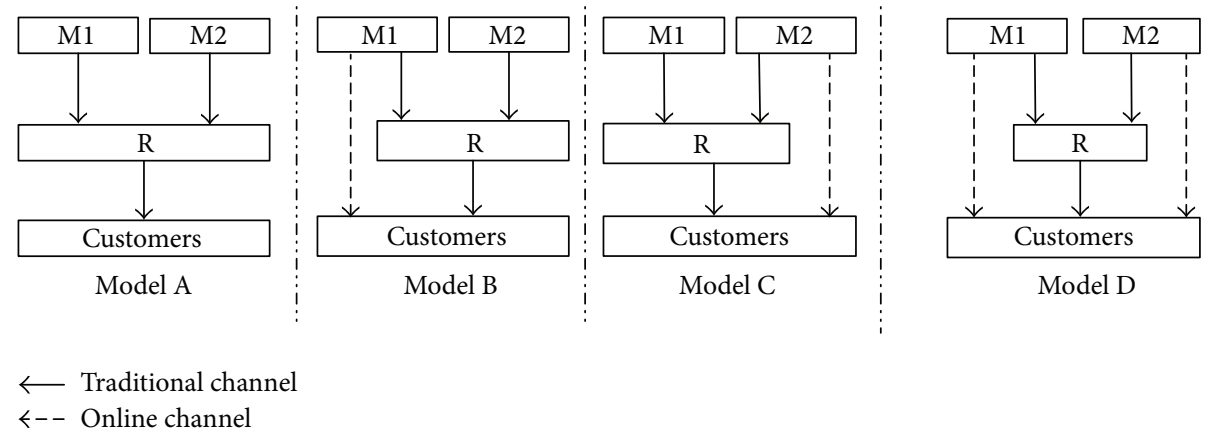

FIGURE 1: Supply chain structures in online channels and retail channels.

retailer, and the retailer sells its products at retail price $p_{i}$ (where $i=1,2$, representing different manufacturers and retailers).

We assume that manufacturer $i(i=1,2)$ sells different products to unique retailer $\mathrm{R}$. Wholesale price is determined as $w_{i}$, and retailer $\mathrm{R}$ sells the products to consumers in price $p_{i}$. The price under online channel is $p_{o i}(i=1,2) ; D_{i}$ represents market demand of different products; $D_{o i}$ is on behalf of the market demand of products under the online channels, and $A_{i}$ is the basic demand for each product.

We use the consumer utility function established by Cai [5] to obtain a different product demand function as follows:

$$
U \equiv \sum_{i=1,2}\left(A_{i} D_{i}-\frac{D_{i}^{2}}{2}\right)-\theta D_{1} D_{2}-\sum_{i=1,2} p_{i} D_{i}
$$

where $\theta(0 \leq \theta<1)$ denotes the product's substitutability. When $\theta=0$, the products are purely monopolistic; when $\theta$ goes to 1 , the products converge to purely substitutable. Maximization of (1) yields the demand function of two products as follows:

$$
D_{i}=\frac{A_{i}-\theta A_{3-i}-p_{i}+\theta p_{3-i}}{1-\theta^{2}}, \quad i=1,2 .
$$

For simplicity, we assume that the manufacturer's production costs and online channels operating costs are zero and assume that the market demand for the basic product $i=(1,2)$ is $A_{i}=1$, being used to reflect that the two channels are symmetrical.

We have the following notations $(i=1,2)$ :

$\eta_{1}$ : the proportion of basic demand in online channel for manufacturer 1 .

$\eta_{2}$ : the proportion of basic demand in online channel for manufacturer 2 .

$\Pi_{m i}:$ the profit in traditional channels for manufacturer $i$.
$\Pi_{o i}:$ the profit in online channels for manufacturer $i$.

$\Pi_{i}$ : the profit in the whole supply chain for manufacturer $i$.

$\Pi_{r}$ : the profit for retailers.

Therefore, the profit function of manufacturers and their online channels and retailers can be written as

$$
\begin{aligned}
\Pi_{m i} & =w_{i} D_{i}, \\
\Pi_{o i} & =p_{o i} D_{o i}, \\
\Pi_{i} & =\Pi_{m i}+\Pi_{o i}, \\
\Pi_{r} & =\sum_{i=1}^{2}\left(p_{i}-w_{i}\right) D_{i} .
\end{aligned}
$$

\section{Model Analysis}

3.1. Model A: Dual-Channel Structure (MA). In the MA structure, two manufacturers offer their products to the retailer, with neither being open online channels, and consumers can only purchase products through retailer $\mathrm{R}$. At this point, the order of decision-making is manufacturers M1 and M2 make their wholesale prices $w_{1}$ and $w_{2}$, respectively. After obtaining the wholesale price of both products, retailers launch the retail prices $p_{1}$ and $p_{2}$, at the same time. According to (2), we know that the demand of the product is

$$
\begin{aligned}
& D_{1}=\frac{1-\theta-p_{1}+\theta p_{2}}{1-\theta^{2}}, \\
& D_{2}=\frac{1-\theta-p_{2}+\theta p_{1}}{1-\theta^{2}} .
\end{aligned}
$$

Therefore, the profit function for retailer $\mathrm{R}$ is

$$
\Pi_{r}=\left(p_{1}-w_{1}\right) D_{1}+\left(p_{2}-w_{2}\right) D_{2}
$$

The profit function for manufacturers is $\Pi_{i}^{\mathrm{MA}}=\Pi_{m i}^{\mathrm{MA}}=$ $w_{i} D_{i}, i=(1,2)$. 
Lemma 1. Under the MA structure, two manufacturers offer their own products to the retailer, and the optimal wholesale and sales prices are

$$
\begin{aligned}
& w_{i}^{M A^{*}}=\frac{1-\theta}{2-\theta}, \\
& p_{i}^{M A^{*}}=\frac{3-2 \theta}{2(2-\theta)} .
\end{aligned}
$$

Proof. See Appendix in online supplemental file in Supplementary Material available online at http://dx.doi.org/10.1155/ 2015/424181.

It is easy to verify that the retail price is not lower than the wholesale price $w_{i}^{\mathrm{MA}^{*}} \leq p_{i}^{\mathrm{MA}^{*}}$ as we have $(1-\theta) /(2-\theta) \leq$ $(3-2 \theta) / 2(2-\theta)$.

3.2. Model B: Dual-Channel Structure (MB). In the MB structure, manufacturers M1 and M2 set wholesale prices, $w_{1}$ and $w_{2}$, at the same time, and manufacturer M1 sets its price in online channel $p_{o 1}$. After obtaining $w_{1}, w_{2}$, and $p_{o 1}$, retailers decide the retail prices as $p_{1}$ and $p_{2}$. With the demand function model we obtained earlier, a demand function after the introduction of direct sales channels exists as follows:

$$
D_{(i, o i)} \equiv \begin{cases}\frac{1-\theta-p_{1}+\theta\left(p_{2}+p_{o 1}\right)}{1-\theta^{2}} & (i=1) \\ \frac{1-\theta+\theta\left(p_{1}+p_{o 1}\right)-p_{2}}{1-\theta^{2}} & (i=2) \\ \frac{\eta_{1}(1-\theta)+\theta\left(p_{1}+p_{2}\right)-p_{o 1}}{1-\theta^{2}} & (o i=o 1) .\end{cases}
$$

The profits function for manufacturers is

$$
\begin{aligned}
& \Pi_{1}^{\mathrm{MB}}=\Pi_{m 1}^{\mathrm{MB}}+\Pi_{o 1}^{\mathrm{MB}}=w_{1} D_{1}+p_{o i} D_{o 1}, \\
& \Pi_{2}^{\mathrm{MB}}=\Pi_{m 2}^{\mathrm{MB}}=w_{2} D_{2} .
\end{aligned}
$$

Lemma 2. Under the MB structure, two manufacturers offer their own products to retailers, and only manufacturer M1 launches online channel. The optimal wholesale and sales prices are

$$
\begin{aligned}
& w_{1}^{M B^{*}}=\frac{(1-\theta)\left(8-\left(4-8 \eta_{1}\right) \theta-\left(3+6 \eta_{1}\right) \theta^{2}-\left(3+2 \eta_{1}\right) \theta^{3}\right)}{2\left(8-8 \theta-15 \theta^{2}+5 \theta^{3}+4 \theta^{4}\right)}, \\
& w_{2}^{M B^{*}}=\frac{(1-\theta)\left(4-2\left(3-\eta_{1}\right) \theta+\left(1-2 \eta_{1}\right) \theta^{2}\right)}{8-16 \theta+\theta^{2}+4 \theta^{3}}, \\
& p_{1}^{M B^{*}}=\frac{24-4\left(7-4 \eta_{1}\right) \theta-\left(15+22 \eta_{1}\right) \theta^{2}+\left(7+2 \eta_{1}\right) \theta^{3}+\left(6+4 \eta_{1}\right) \theta^{4}}{4\left(8-8 \theta-15 \theta^{2}+5 \theta^{3}+4 \theta^{4}\right)} \\
& p_{2}^{M B^{*}}=\frac{24-4\left(7-3 \eta_{1}\right) \theta-2\left(11+6 \eta_{1}\right) \theta^{2}+\left(19-6 \eta_{1}\right) \theta^{3}+\left(1+6 \eta_{1}\right) \theta^{4}}{4\left(8-8 \theta-15 \theta^{2}+5 \theta^{3}+4 \theta^{4}\right)}, \\
& p_{o 1}^{M B^{*}}=\frac{(1-\theta)(2+\theta)\left(7 \theta-5 \theta^{2}+2 \eta_{1}\left(2-3 \theta+\theta^{2}\right)\right)}{2\left(8-8 \theta-15 \theta^{2}+5 \theta^{3}+4 \theta^{4}\right)} .
\end{aligned}
$$

Proof. See Appendix in online supplemental file.

The retail price is not lower than the wholesale price, $w_{i}^{\mathrm{MB}^{*}} \leq p_{i}^{\mathrm{MB}^{*}}$ as we have $\theta \in(0,113 / 200)$.

3.3. Model C: Dual-Channel Structure (MC). In MC structure, manufacturers $\mathrm{M} 1$ and $\mathrm{M} 2$ determine wholesale prices as $w_{1}$ and $w_{2}$. Meanwhile, the manufacturer M2 sets its price in online channel $p_{o 2}$. After obtaining $w_{1}, w_{2}$, and $p_{o 2}$, retailers decide the retail prices as $p_{1}$ and $p_{2}$. Similar with
Model B, a demand function after the introduction of direct sales channels exists:

$$
D_{(i, o i)} \equiv \begin{cases}\frac{1-\theta-p_{1}+\theta\left(p_{2}+p_{o 2}\right)}{1-\theta^{2}} & (i=1) \\ \frac{1-\theta+\theta\left(p_{1}+p_{o 2}\right)-p_{2}}{1-\theta^{2}} & (i=2) \\ \frac{\eta_{2}(1-\theta)+\theta\left(p_{1}+p_{2}\right)-p_{o 2}}{1-\theta^{2}} & (o i=o 2) .\end{cases}
$$


The profits function for manufacturers is

$$
\begin{aligned}
& \Pi_{1}^{\mathrm{MC}}=\Pi_{m 1}^{\mathrm{MC}}=w_{1} D_{1}, \\
& \Pi_{2}^{\mathrm{MC}}=\Pi_{m 2}^{\mathrm{MC}}+\Pi_{o 2}^{\mathrm{MC}}=w_{2} D_{2}+p_{o 2} D_{o 2} .
\end{aligned}
$$

Lemma 3. Under the MC structure, two manufacturers offer their own products to retailers, and only manufacturer M2 launches online channels. The optimal wholesale and sales prices are

$$
\begin{aligned}
& w_{1}^{M C^{*}}=\frac{(1-\theta)\left(4-2\left(3-\eta_{2}\right) \theta+\left(1-2 \eta_{2}\right) \theta^{2}\right)}{8-16 \theta+\theta^{2}+4 \theta^{3}} \\
& w_{2}^{M C^{*}}=\frac{(1-\theta)\left(8-\left(4-8 \eta_{2}\right) \theta-\left(3+6 \eta_{2}\right) \theta^{2}-\left(3+2 \eta_{2}\right) \theta^{3}\right)}{2\left(8-8 \theta-15 \theta^{2}+5 \theta^{3}+4 \theta^{4}\right)} \\
& p_{1}^{M C^{*}}=\frac{24-4\left(7-3 \eta_{2}\right) \theta-2\left(11+6 \eta_{2}\right) \theta^{2}+\left(19-6 \eta_{2}\right) \theta^{3}+\left(1+6 \eta_{2}\right) \theta^{4}}{4\left(8-8 \theta-15 \theta^{2}+5 \theta^{3}+4 \theta^{4}\right)}, \\
& p_{2}^{M C^{*}}=\frac{24-4\left(7-4 \eta_{2}\right) \theta-\left(15+22 \eta_{2}\right) \theta^{2}+\left(7+2 \eta_{2}\right) \theta^{3}+\left(6+4 \eta_{2}\right) \theta^{4}}{4\left(8-8 \theta-15 \theta^{2}+5 \theta^{3}+4 \theta^{4}\right)} \\
& p_{o 2}^{M C^{*}}=\frac{(1-\theta)(2+\theta)\left(7 \theta-5 \theta^{2}+2 \eta_{2}\left(2-3 \theta+\theta^{2}\right)\right)}{2\left(8-8 \theta-15 \theta^{2}+5 \theta^{3}+4 \theta^{4}\right)}
\end{aligned}
$$

Proof. See Appendix in online supplemental file.

The retail price is not lower than the wholesale price, $w_{i}^{\mathrm{MC}^{*}} \leq p_{i}^{\mathrm{MC}^{*}}$, as we have $\theta \in(0,113 / 200)$.

3.4. Model D: Dual-Channel Structure (MD). In the MD structure, manufacturers M1 and M2 determine wholesale prices as $w_{1}$ and $w_{2}$, at the same time; manufacturers M1 and M2 both launch their online channels and decide the online channel price as $p_{o 1}$ and $p_{o 2}$. After obtaining $w_{1}$ and $w_{2}$ and $p_{o 1}$ and $p_{o 2}$, retailer $\mathrm{R}$ decides the retail prices as $p_{1}$ and $p_{2}$. Similar to Models B and C, a demand function of dual channels exists:

$$
\begin{aligned}
& D_{(i, o i)} \\
& \equiv \begin{cases}\frac{1-\theta-p_{1}+\theta\left(p_{2}+p_{o 1}+p_{o 2}\right)}{1-\theta^{2}} & (i=1) \\
\frac{1-\theta+\theta\left(p_{1}+p_{o 1}+p_{o 2}\right)-p_{2}}{1-\theta^{2}} & (i=2) \\
\frac{\eta_{1}(1-\theta)+\theta\left(p_{1}+p_{2}+p_{o 2}\right)-p_{o 1}}{1-\theta^{2}} & (o i=o 1) \\
\frac{\eta_{2}(1-\theta)+\theta\left(p_{1}+p_{2}+p_{o 1}\right)-p_{o 2}}{1-\theta^{2}} & (o i=o 2) .\end{cases}
\end{aligned}
$$

Profits for manufacturers are

$$
\begin{aligned}
& \Pi_{1}^{\mathrm{MB}}=\Pi_{m 1}^{\mathrm{MB}}+\Pi_{o 1}^{\mathrm{MB}}=w_{1} D_{1}+p_{o i} D_{o 1}, \\
& \Pi_{2}^{\mathrm{MC}}=\Pi_{m 2}^{\mathrm{MC}}+\Pi_{o 2}^{\mathrm{MC}}=w_{2} D_{2}+p_{o 2} D_{o 2} .
\end{aligned}
$$

Lemma 4. Under the MD structure, two manufacturers offer their own products to retailers, and both manufactures launch online channels. The optimal wholesale and sales prices are

$$
\begin{aligned}
& w_{1}^{M D^{*}}=2(1-\theta)^{2}\left(16-8\left(3-\eta_{2}-2 \eta_{1}\right) \theta+(2\right. \\
& \left.\left.\quad-24 \eta_{1}\right) \theta^{2}+\left(3-11 \eta_{2}+2 \eta_{1}\right) \theta^{3}\right) \cdot(64-192 \theta \\
& \left.\quad+16 \theta^{2}+240 \theta^{3}-71 \theta^{4}-39 \theta^{5}\right)^{-1}, \\
& w_{2}^{M D^{*}}=2(1-\theta)^{2}\left(16-8\left(3-2 \eta_{2}-\eta_{1}\right) \theta+(2\right. \\
& \left.\left.\quad-24 \eta_{2}\right) \theta^{2}+\left(3+2 \eta_{2}-11 \eta_{1}\right) \theta^{3}\right) \cdot(64-192 \theta \\
& \left.\quad+16 \theta^{2}+240 \theta^{3}-71 \theta^{4}-39 \theta^{5}\right)^{-1}, \\
& p_{1}^{M D^{*}}=\left(96-16\left(19-3 \eta_{2}-4 \eta_{1}\right) \theta+4\left(65-28 \eta_{2}\right.\right. \\
& \left.\quad-48 \eta_{1}\right) \theta^{2}-2\left(1-23 \eta_{2}-92 \eta_{1}\right) \theta^{3}-\left(41-46 \eta_{2}\right. \\
& \left.\left.\quad+54 \eta_{1}\right) \theta^{4}-\left(3+28 \eta_{2}+2 \eta_{1}\right) \theta^{5}\right) \cdot(2(64-192 \theta \\
& \left.\left.\quad+16 \theta^{2}+240 \theta^{3}-71 \theta^{4}-39 \theta^{5}\right)\right)^{-1}, \\
& p_{2}^{M D^{*}}=\left(96-16\left(19-4 \eta_{2}-3 \eta_{1}\right) \theta+4\left(65-48 \eta_{2}\right.\right. \\
& \left.\quad-28 \eta_{1}\right) \theta^{2}-2\left(1-92 \eta_{2}-23 \eta_{1}\right) \theta^{3}-\left(41+54 \eta_{2}\right. \\
& \left.\left.\quad-46 \eta_{1}\right) \theta^{4}-\left(3+2 \eta_{2}+28 \eta_{1}\right) \theta^{5}\right) \cdot(2(64-192 \theta \\
& \left.\left.\quad+16 \theta^{2}+240 \theta^{3}-71 \theta^{4}-39 \theta^{5}\right)\right)^{-1},
\end{aligned}
$$




$$
\begin{aligned}
& p_{o 1}^{M D^{*}}=(1-\theta)\left(4 \eta_{1}\left(8-24 \theta+17 \theta^{2}+3 \theta^{3}-4 \theta^{4}\right)\right. \\
& \quad+\theta\left(56-96 \theta+19 \theta^{2}+15 \theta^{3}\right. \\
& \left.\left.\quad+2 \eta_{2}\left(8-8 \theta-5 \theta^{2}+5 \theta^{3}\right)\right)\right) \cdot\left(64-192 \theta+16 \theta^{2}\right. \\
& \left.\quad+240 \theta^{3}-71 \theta^{4}-39 \theta^{5}\right)^{-1}, \\
& p_{o 2}^{M D^{*}}=(1-\theta)\left(4 \eta_{2}\left(8-24 \theta+17 \theta^{2}+3 \theta^{3}-4 \theta^{4}\right)\right. \\
& \quad+\theta\left(56-96 \theta+19 \theta^{2}+15 \theta^{3}\right. \\
& \left.\left.\quad+2 \eta_{1}\left(8-8 \theta-5 \theta^{2}+5 \theta^{3}\right)\right)\right) \cdot\left(64-192 \theta+16 \theta^{2}\right. \\
& \left.\quad+240 \theta^{3}-71 \theta^{4}-39 \theta^{5}\right)^{-1} .
\end{aligned}
$$

Proof. See Appendix in online supplemental file.

The retail price is not lower than the wholesale price $w_{i}^{\mathrm{MD}^{*}} \leq p_{i}^{\mathrm{MD}^{*}}$ as we have $\theta \in(0,(2 / 13)(6-\sqrt{10}))$.

\section{Equilibrium Analysis}

Models B and C are symmetric channel structures; therefore, we only considered one. Under the three categories of the dual-channel model, we will analyze the optimal pricing decisions, channel demand, and channel profits and further analyze the influence of the introduction of online channels to manufacturers.

4.1. Symmetric Basic Demand. Under this case, we suppose that both manufacturers have the same proportion of basic demand in online direct marketing; that is, $\eta_{1}=\eta_{2}$. The following proposition can be obtained through mathematical analysis of the third section.
Proposition 5. Only when $\theta \in(0,(2 / 13)(6-\sqrt{10}))$ is the manufacturer's wholesale price $w_{i} \geq 0$ in the four-channel model and demand $D_{i}>0$ fulfilled; Models A, B, and D channel can coexist simultaneously. Meanwhile, increasing online sales channels can increase the overall profits of the manufacturers, as the following relationship:

$$
\begin{aligned}
& w_{i}^{M D^{*}}>w_{i}^{M B^{*}}>w_{i}^{M A^{*}}, \\
& D_{i}^{M D^{*}}>D_{i}^{M B^{*}}>D_{i}^{M A^{*}}, \\
& \Pi_{i}^{M D^{*}}>\Pi_{i}^{M B^{*}}>\Pi_{i}^{M A^{*}}, \\
& \Pi_{r}^{M D^{*}}>\Pi_{r}^{M B^{*}}>\Pi_{r}^{M A^{*}} .
\end{aligned}
$$

Proof. See Appendix in online supplemental file.

We can conclude that two manufacturers increasing online access simultaneously can obtain more profits than individual manufacturers during online channels. The more alternatives of the products are available, the higher the profits are through online channels.

Proposition 6. When $\theta \in((2 / 13)(6-\sqrt{10}), 113 / 200)$, manufacturers' wholesale prices under MD channel mode are negative, which cannot satisfy reality. Only Models A, B, and C exist on the market.

Proof. See Appendix in online supplemental file.

When $\theta \in((2 / 13)(6-\sqrt{10}), 113 / 200)$, we can get $\Pi_{i}^{\mathrm{MB}^{*}}>$ $\Pi_{i}^{\mathrm{MA}^{*}}$. Even though manufacturer $m_{2}$ does not launch online channels, the profits under Model MB are more than that under Model MA:

$$
\Pi_{\Delta m_{2}}=\Pi_{2}^{\mathrm{MB}^{*}}-\Pi_{2}^{\mathrm{MA}^{*}}=\frac{(\theta-1)\left(1 /(2-\theta)^{2}-(4-\theta(6-2 \eta(1-\theta)-\theta))^{2} /\left(8-\theta\left(16-\theta-4 \theta^{2}\right)\right)^{2}\right)}{2(1+\theta)}
$$

Manufacturer $m_{1}$ that opened online channels gains more profits than manufacturer $m_{2}$ :

$$
\Pi_{\Delta}=\Pi_{1}^{\mathrm{MB}^{*}}-\Pi_{2}^{\mathrm{MB}^{*}}=\frac{\theta^{2}\left(35-18 \theta-5 \theta^{2}\right)+4 \eta^{2}(1-\theta)^{2}\left(4-\theta^{2}\right)+12 \eta \theta\left(4-5 \theta+\theta^{3}\right)}{8(1+\theta)^{2}\left(8-16 \theta+\theta^{2}+4 \theta^{3}\right)} .
$$

Thus, when the substitution of the products remains at a certain range, launching online channels can be beneficial to the opposite, which will benefit both sides.

Proposition 7. When $\theta>113 / 200$, the online channel price under online channels is $p_{o 1}^{M B^{*}}<0$, but it does not satisfy reality. Only traditional channels MA exist on the market; the profits in online channels can be affected by alternatives of the products and online channels do not apply to any situation.

Proof. See Appendix in online supplemental file. 
4.2. Asymmetric Basic Demand. Under this case, we suppose that both manufacturers have the different proportion of basic demand in online direct marketing; that is, $\eta_{1} \neq \eta_{2}$. The model involves various demand combinations and constraint conditions. Therefore, to analyze the models more intuitively, several specific examples of the models are given below to analyze the influence of the replacement rate of products and distribution rate of online demand on manufacturers and retailers and to examine how both rates affect the access tactics for online channels. The parameters meet $\theta \in(0,1)$; $\eta_{1} \in(0,1) ; \eta_{2} \in(0,1)$. We can see that when $\eta_{1} \neq \eta_{2}$, for example, $\eta_{1}=1 / 2, \eta_{2}=1 / 4$, the conclusion meets our earlier results.

4.3. Analysis of Consumer Welfare and Tobacco Control. Based on the earlier conclusion, we further compared the levels of consumer welfare under Models MA, MB, and MD. In the MA channel mode, when $\theta \in(0,1)$, the consumer utility value $U^{\mathrm{MA}^{*}}>0$, and with the increase of $\theta$, the value of $U^{\mathrm{MA}}$ also increased gradually. In the online channel model, the utility value of $U^{\mathrm{MB}^{*}}$ and $U^{\mathrm{MD}^{*}}$ indicated a decrease after an increase, and the utility value of the online channels is larger when the alternative of products is smaller. We also compared the effects $\eta$ on consumer welfare. In addition to increasing $\eta$, the utility value of $U^{*}$ decreases, while the replacement rate of products $\theta$ is constantly reduced.

Therefore, we can conclude that when the substitution of products is smaller, consumer's welfare in the online channel is higher than in traditional channels, and the effect of tobacco control is worse. With the increase in the product's substitution, the consumer's welfare in traditional channel becomes increasingly higher than in the online channels, while the consumer's welfare becomes much lower, with tobacco control having better effect than in traditional channels.

\section{Conclusions and Future Research}

This paper takes tobacco suppliers and retailers as its main objects. Manufacturers have to not only decide whether to use online channels when they have only one common retailer but also consider carefully how much profit they can gain from online channels. This paper shows that not all companies who open online channels can gain profits. The key element for opening online channels is the substitution of products and distribution of online channels demand. Manufacturer can gain higher profits with selling smaller substitution products, including that through online channel. When the substitution of the products is beyond a certain range, it is unprofitable to open online channels. Completely abandoning traditional channels to open online channels also results in unprofitable prospects for manufacturers.

We analyzed the impact of tobacco control under different channels on products control. In traditional channels, as the substitutability of products increased, better consumer welfare resulted in a more negative prospect for tobacco control. Under online channels, the increase in substitutability of the products and the demand for products in online channels resulted in poorer consumer welfare, which is a more optimistic prospect for tobacco control.

Although this paper compares the profits of suppliers and a retailer in traditional and online channels as well as the consumer welfare levels in different channels, the paper has several deficiencies and areas that can be considered for future research. First, this paper assumes the existence of only two manufacturers and one retailer. Future studies are expected to take into account multiple suppliers and retailers, and that assumption will be practical. Secondly, to facilitate research, this paper does not consider the more general stochastic demand newsboy model and uses the linear demand function with the assumption that the strength of two channels is symmetrical. Third, this paper does not account for cost. Further studies could consider operating costs, such as shipping cost, under traditional and online channels, and investigate the efficiency of different operation modes under different shipping policies. The competition between traditional and online channels will also be important research directions in the future. Lastly, it is important for the tobacco firms to take the corporate social responsibility, so it is worth for the tobacco firm to study how to balance the business development and corporate social responsibility.

\section{Conflict of Interests}

The authors declare that there is no conflict of interests regarding the publication of this paper.

\section{Acknowledgments}

This work is supported by National Natural Science Foundation of China Grant nos. U1204701, 71301045, and 71571117 and Innovation Ability Construction projects for Shanghai University (15590501800).

\section{References}

[1] A. A. Tsay and N. Agrawal, "Channel conflict and coordination in the E-commerce age," Production and Operations Management, vol. 13, no. 1, pp. 93-110, 2004.

[2] S. Y. Park and H. T. Keh, "Modelling hybrid distribution channels: a game-theoretic analysis," Journal of Retailing and Consumer Services, vol. 10, no. 3, pp. 155-167, 2003.

[3] W.-Y. K. Chiang, D. Chhajed, and J. D. Hess, "Direct marketing, indirect profits: a strategic analysis of dual-channel supplychain design," Management Science, vol. 49, no. 1, pp. 1-20, 2003.

[4] N. Kumar and R. Ruan, "On manufacturers complementing the traditional retail channel with a direct online channel," Quantitative Marketing and Economics, vol. 4, no. 3, pp. 289323, 2006.

[5] G. G. Cai, "Channel selection and coordination in dual-channel supply chains," Journal of Retailing, vol. 86, no. 1, pp. 22-36, 2010.

[6] D.-Q. Yao and J. J. Liu, "Competitive pricing of mixed retail and e-tail distribution channels," Omega, vol. 33, no. 3, pp. 235-247, 2005.

[7] K. Cattani, W. Gilland, H. S. Heese, and J. Swaminathan, "Boiling frogs: pricing strategies for a manufacturer adding a direct channel that competes with the traditional channel," 
Production and Operations Management, vol. 15, no. 1, pp. 4056, 2006.

[8] G. P. Cachon and A. G. Kök, "Competing manufacturers in a retail supply chain: on contractual form and coordination," Management Science, vol. 56, no. 3, pp. 571-589, 2010.

[9] R. Friberg, M. Ganslandt, and M. Sandström, Pricing Strategies in E-Commerce: Bricks vs. Clicks, IUI, The Research Institute of Industrial Economics, 2001.

[10] R. Zhang, B. Liu, and W. Wang, "Pricing decisions in a dual channels system with different power structures," Economic Modelling, vol. 29, no. 2, pp. 523-533, 2012.

[11] B. Liu, G. G. Cai, and A. A. Tsay, "Advertising in asymmetric competing supply chains," Production and Operations Management, vol. 23, no. 11, pp. 1845-1858, 2014.

[12] B. Li, M. Zhu, Y. Jiang, and Z. Li, "Pricing policies of a competitive dual-channel green supply chain," Journal of Cleaner Production, 2015.

[13] T.-H. Chen, "Effects of the pricing and cooperative advertising policies in a two-echelon dual-channel supply chain," Computers \& Industrial Engineering, vol. 87, no. 9, pp. 250-259, 2015.

[14] M. Khouja and J. Zhou, "Channel and pricing decisions in a supply chain with advance selling of gift cards," European Journal of Operational Research, vol. 244, no. 2, pp. 471-489, 2015.

[15] J. Cao, K. C. So, and S. Yin, "Impact of an 'online-to-store' channel on demand allocation, pricing and profitability," European Journal of Operational Research, vol. 248, no. 1, pp. 234-245, 2016. 


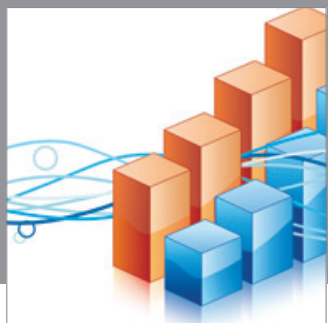

Advances in

Operations Research

mansans

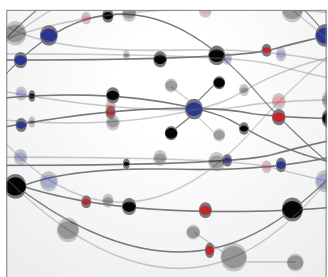

The Scientific World Journal
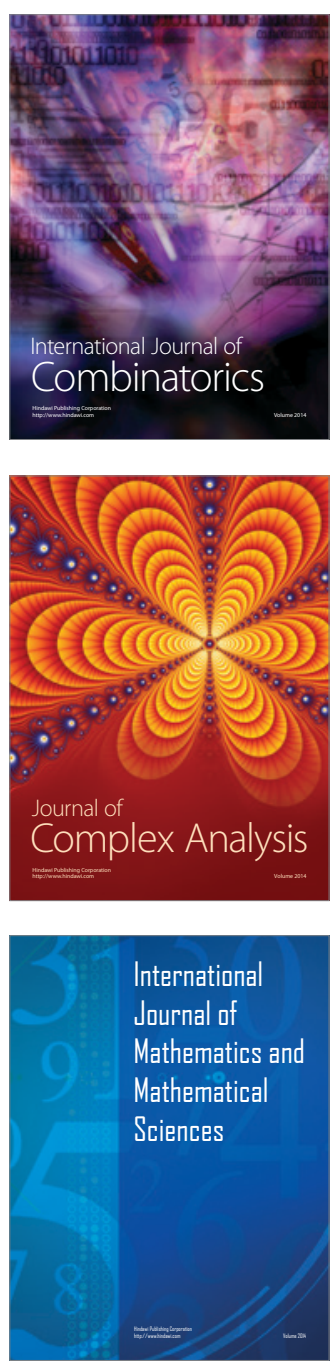
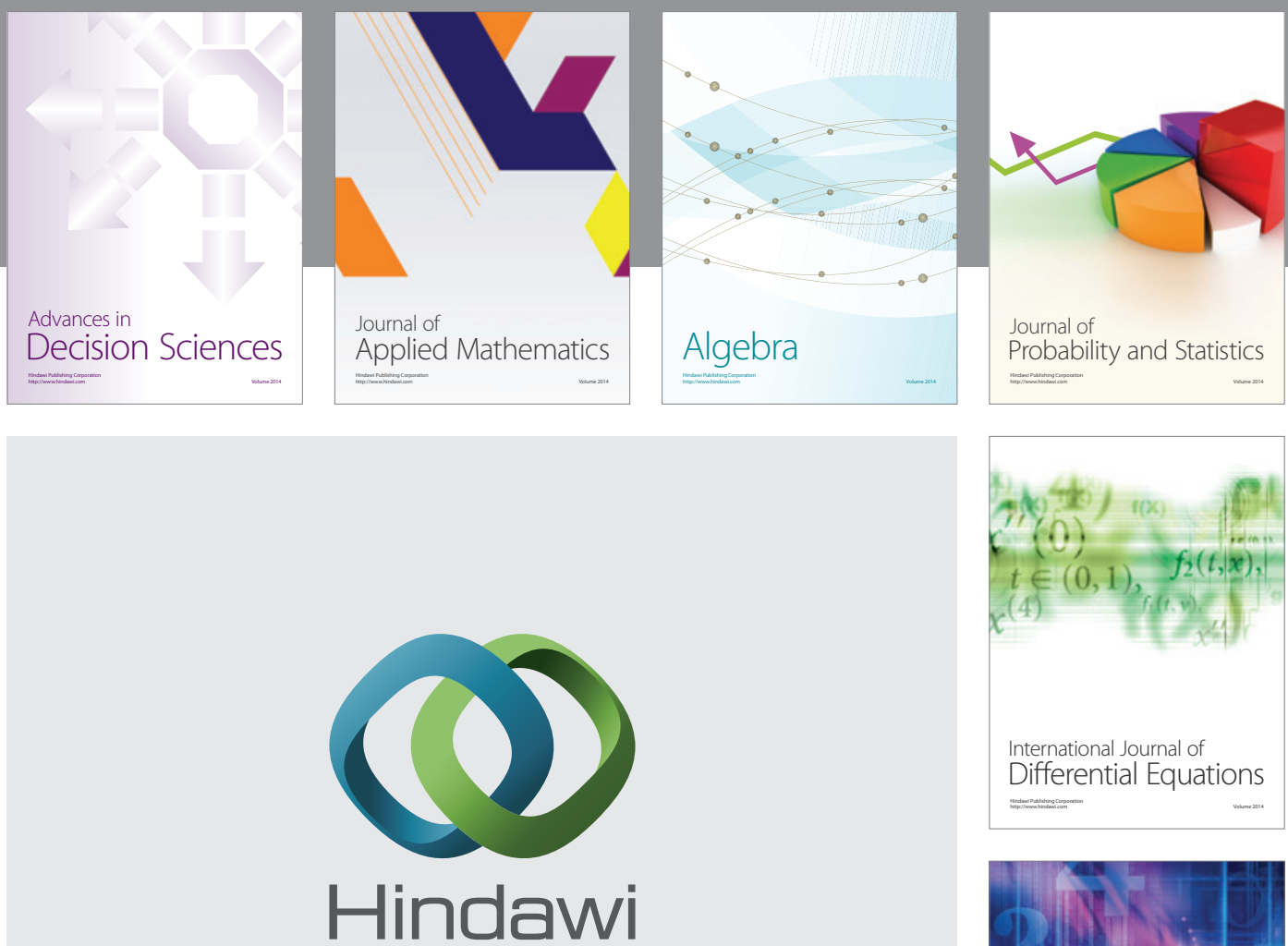

Submit your manuscripts at http://www.hindawi.com
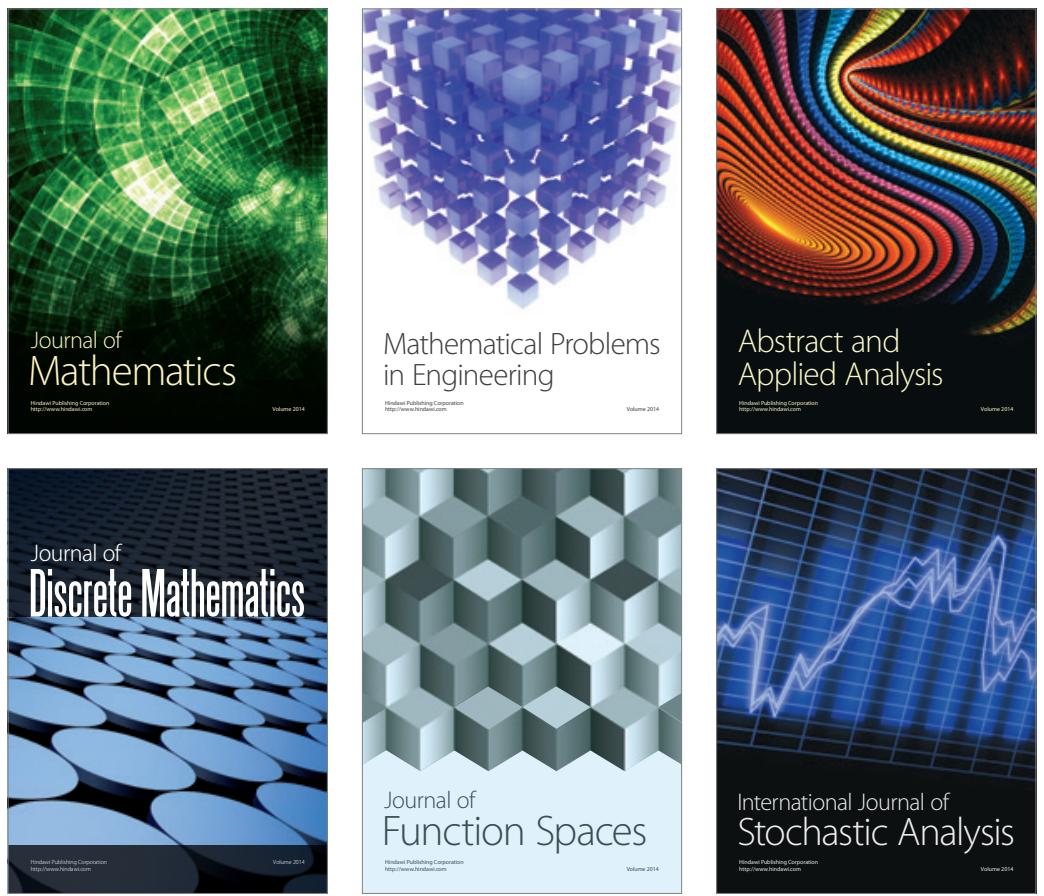

Journal of

Function Spaces

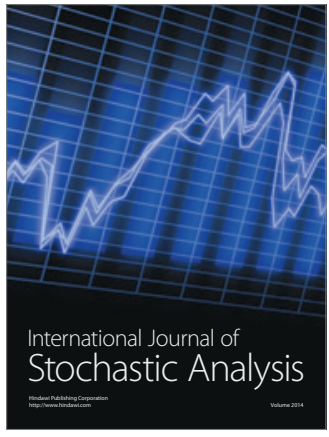

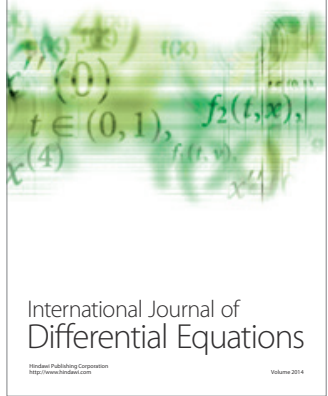
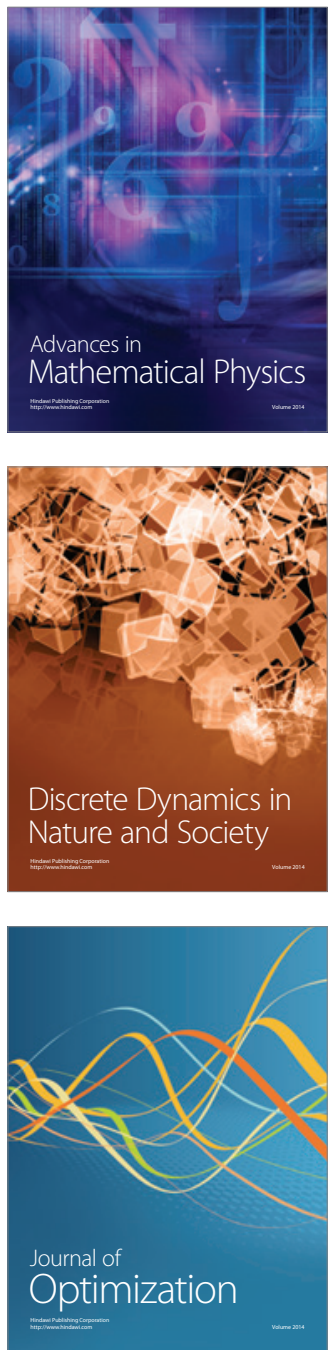